\title{
Bilateral Norrie's disease in identical twins
}

\author{
K Sukumaran
}

\begin{abstract}
A case of Norrie's disease in an identical twins is reported. No positive family history was obtained. The couple had no other children. The older of the twins died at the age of 9 months of uncertain cause. To the best of my knowledge this is the first case of Norrie's disease reported in Malaysia. And its occurrence in an identical twins is very rare.
\end{abstract}

A pair of male identical Chinese twins, $A$ and $B$ aged 3 months, were brought by their parents to the Eye Clinic of the University Hospital, Kuala Lumpur, Malaysia, with a complaint of bilateral white pupil.

On examination, twin A, the older, had a left cloudy cornea of one week's duration. The birth weight was $1360 \mathrm{~g}$ and the child was born prematurely at the seventh month of an uncomplicated pregnancy by a spontaneous vaginal delivery in a private hospital near by. Oxygen was given for 20 days. Hepatosplenomegaly was present; the liver was enlarged $4 \mathrm{~cm}$ and the spleen $1 \mathrm{~cm}$.

The child was examined under general anaesthesia. There was central stromal opacity of the left cornea, and the left fundal view was hazy. However, there was a diffuse white growth on both the retinae. There were areas of adhesions between the iris and the anterior capsule of the lens in the left eye. Neovascularisation of the iris was also present. The anterior chamber was shallow. Similar findings were seen in his right eye. The horizontal and vertical corneal diameters in both eyes were within normal limits. The intraocular pressures of the left and right eyes were 21.9 and $21.3 \mathrm{mmHg}$ respectively by Schiøtz tonometer. A clinical diagnosis of bilateral retinoblastoma was made, and his left eye was enucleated. Histopathological examination did not reveal a tumour but retinal dysplasia.

Twin B, the younger, had haziness of both corneas of one week's duration. The birth weight was also $1360 \mathrm{~g}$, and the baby was born about 16 minutes after the first twin. This child also received oxygen for the first 20 days of life.

The child was examined under general anaesthesia. Both the fundi, though poorly visible owing to corneal haziness, showed whitish growths in the retinae with poor details. Rubeosis iridis was present in both eyes, and the anterior chambers in both eyes were shallow. The horizontal and vertical diameters in both eyes were within normal limits. The intraocular pressures of right and left eyes were 21.9 and $10.9 \mathrm{mmHg}$ respectively by Schiøtz tonometer. A clinical diagnosis of bilateral retinoblastoma was made, and his right eye was enucleated. Histopathological examination revealed retinal dysplasia of the right eye.

The anthropometric chart was similar in both infants. The head circumference was 50th percentile, length was less than $3 \mathrm{rd}$ percentile, and the weight less than 10th percentile. The percentiles on this anthropometric chart were based on data from H C Stuart and associates, Harvard School of Public Health, Boston.

The first twin was not so active as the second. In view of the bilateral eye involvement of both infants, specimens were sent to the Institute of Ophthalmology, London, for an expert opinion from Professor A Garner. His report was as follows.

Twin A. 'The retina was completely detached and whilst there was much distortion due to folding, I think there may also be some true dysplastic rosette formation. The subretinal space is filled with serohaemorrhagic exudate and there is some hyperplasia of the ciliary processes. The surface of the detached retina is covered in part by a layer of vascularised fibrous tissue which is, in turn, adherent to the posterior capsule of the lens. One leaf of the iris is pressed against the back of the cornea, which is slightly oedematous.'

Twin $B$. 'The only difference is an absence of iris displacement. These histological findings occurring in male infants are strongly suggestive of the X-linked Norrie's disease in which corneal opacities, elongated ciliary processes, retinal detachment and dysplasia with haemorrhagic sub-retinal exudate are all described.'

\section{Discussion}

Atrophia oculi congenita was a type of congenital blindness first described by the Danish ophthalmologist, G Norrie,' in 1927 after having surveyed the causes of blindness in Denmark. The term 'Norrie's disease' was actually proposed by Warburg for congenital bilateral pseudotumour of retina with recessive $\mathrm{X}$-linked chromosomal transmission. ${ }^{2}$ The gene is carried by females and the disease affects only males. ${ }^{3}$

The exact pathogenesis of Norrie's disease is not clear. Warburg believed that a genetically determined biochemical defect induces an early arrest in retinal development, with associated malformation of the primary and secondary vitreous. ${ }^{+}$Neuroectodermal changes also occur in the cerebral cortex and auditory nerve. ${ }^{4}$ Clinical and histopathological similarities between Norrie's and Coats's disease have been suggested. ${ }^{5}$

Norrie's disease, which is rare, ${ }^{6}$ has been reported in other parts of the world. ${ }^{7}$ To the best of my knowledge this is the first case reported in Malaysia, and possibly its occurrence in identical twins is very rare.

Though varying degrees of hearing impairment and mental retardation have been described, this pair of twins clinically revealed no such abnormality at the time of examination. 
There was no family history of blindness, and this was the mother's first pregnancy. Since this disease is not common, a strong diagnosis of retinoblastoma was considered and hence the enucleation. CT scan was not available in the hospital then. The problem of differentiating a pseudoglioma from retinoblastoma may be difficult in infants and children, and a thorough knowledge of the family history is of great value. Unfortunately, the parents of this pair of twins failed to keep follow-up appointments, but we know from them that the elder of the twins died at 9 months of age of undetermined cause. Permission to photograph the twins before and after enucleation was refused.

1 Norrie G. Causes of blindness in children. Twenty five years experience of Danish institutes for the blind. Acta Opthalmol (Kbh) 1927; 5: 357-86

2 Warburg M. Norrie's disease: a new hereditary bilateral pseudotumour of the retina. Acta Ophthalmol (Kbh) 1961; 39: 757-72.

3 Taylor PJ, Coates T, Newhouse ML. Episkopi blindness: hereditary blindness in a Greek Cypriot family. Br 7 Ophhereditary blindness in a Greek Cypriot family. Br f Oph-

Warburg $M$. Norrie's disease and falciform detachment of the retina. In: Goldberg M, ed. Genetic and metabolic aspects of eve disease. Boston: Little, Brown, 1974: 441-6.

5 Blodi F, Hunter, W. Norrie's disease in North America. Doc Ophthalmol 1969; 26: 434-50.

6 Norrie's disease: a congenital progressive oculo-acousticocerebral degeneration. Acta Ophthalmol (Kbh) 1966;89 (suppl): $1-47$.

7 Axel C. Norrie's disease. Am f Ophthalmol 1968; 66: 328-32. 